\title{
UM ESTUDO DAS TIRAS DE HUMOR NA SALA DE AULA: ANÁLISE DA INTERAÇÃO ENTRE O EU E O OUTRO SOB A PERSPECTIVA DO CÍRCULO DE BAKHTIN
}

\author{
A STUDY OF COMIC STRIPS IN THE CLASSROOM: ANALYSIS OF THE \\ INTERACTION BETWEEN "ME" AND THE "OTHER" FROM A BAKHTIN CIRCLE \\ PERSPECTIVE
}

\author{
Jessica de Castro Gonçalves \\ UNESP - Araraquara
}

\begin{abstract}
RESUMO: O presente trabalho propõe um estudo das tiras de humor no contexto da sala de aula. Este volve os olhares para a produção de sentidos nas tiras da Mafalda, na relação com o discurso do outro, ao analisar o discurso das mesmas frente ao sujeito aluno e às relações existentes no contexto da sala de aula e da avaliação escolar. Objetiva-se, neste artigo, mostrar a importância da alteridade na produção de sentidos e significações. A perspectiva teórica deste texto é a do Círculo de Bakhtin e compreende os conceitos de sujeito, significação, discurso e alteridade. Segundo as perspectiva bakhtiniana, o sujeito é um ser social constituído de língua e linguagem. Ele só se torna sujeito em relação a outros sujeitos, não havendo o acabamento da constituição do ser sem a relação com o outro. Daí a importância de verificarmos o posicionamento dos alunos diante dos discursos de seus outros (as tiras da Mafalda e o professor). Este estudo estabelece, dessa forma, a relação entre a alteridade e a produção de sentido a partir da análise de discursos das tiras, bem como das relações entre sujeitos no contexto escolar.
\end{abstract}

PALAVRAS-CHAVE: tiras de humor; discurso; alteridade; sujeito; ato.

ABSTRACT: This paper proposes a study of the comic strips in the context of the classroom. The intention is to think about the production of the meaning in the Mafalda comic strips from relation to the discourse of the other, by analyzing the strips discourse forward the students and the relationships within the context of the classroom and school evaluation. The objective of this article is to show the importance of otherness in the production of meaning and signification. The theoretical perspective of this text is the Bakhtin Circle studies and it reflects about the concepts of subject, meaning, speech and otherness. According to Bakhtin's perspective, the subject is social constituted of language. He only becomes a subject in the relation to other subjects, where you cannot finish the constitution of being without the relationship with the other. It is very important to verify the placement of students in front of their other speeches (strips of Mafalda and the teacher). This study establishes, therefore, the relationship between otherness and the production of meaning, from the discourse analysis of the strips as well as the relations between the individuals in the school context.

KEYWORDS: comic strips; discourse; otherness; subject; act. 


\section{Revista do SELL}

v. $4, n^{\circ} .1$

ISSN: $1983-3873$

1. O gênero tira de humor e a escola

O Círculo de Bakhtin, Medviédev, Volochinov desenvolveu, ao longo de seus estudos, reflexões sobre as interações únicas e inúmeras estabelecidas entre sujeitos. Únicas e inúmeras devido à sua ocorrência em variados contextos e entre diferentes sujeitos social, histórica e culturalmente situados. Cada uma dessas se materializa por meio da linguagem em enunciados concretos que assumem configurações segundo os diversos campos da atuação do homem. Como consequência, muitos são os gêneros discursivos envolvidos na comunicação.

Conforme as discussões do círculo russo (Bakhtin, Medviédev, Volochinov), os gêneros diferenciam entre si segundo o estilo, a forma e a composição, utilizados com diversos propósitos e intenções em cada ato comunicativo. No entanto, um mesmo gênero discursivo configura-se segundo os diferentes contextos em que ocorre e as relações entre os sujeitos ali estabelecidas. De acordo com a perspectiva dialógica da linguagem, discutida pelo Círculo, os discursos constroem-se e descontroem-se na relação com os diversos outros envolvidos na interação.

As tiras de humor são um gênero discursivo bastante constante em nosso cotidiano. Segundo Ramos (2010) estas são um dos vários gêneros sob o rótulo de quadrinhos. Presentes em diferentes contextos como blogs, sites de relacionamento, livros didáticos, textos jornalísticos e avaliações, são utilizadas com diferentes propósitos. São caracterizadas da seguinte maneira

a temática atrelada ao humor é uma das principais características do gênero tira cômica. Mas há outras: trata-se de um texto curto (dada a restrição do formato retangular, que é fixo), construído em um ou mais quadrinhos, com presença de personagens fixos ou não, que cria uma narrativa com desfecho inesperado no final. (RAMOS, 2010, p.24)

Conhecidas pelo caráter humorístico, as tiras se compõem, como gênero, na relação entre o verbal e o visual e é no diálogo entre essas duas linguagens que ocorre a arquitetônica da tira, de forma a produzir significações. Mendonça (2010) destaca a presença dessa fusão entre imagem e texto verbal nas sequências dos quadrinhos e considera-a grande responsável pela produção de sentidos.

Ramos (2010) discute também a linguagem dos quadrinhos caracterizando-a como autônoma, já que segundo ele, estes possuem mecanismos próprios que representam os 


\section{Revista do SELL}

v. $4, n^{\circ} .1$

ISSN: $1983-3873$

elementos narrativos. De acordo com o autor, os balões, as cores, as onomatopeias, os aspectos gráficos das letras e a forma de representação do pensamento e da fala, entre outros elementos, possuem significados e funções no desenrolar da narrativa.

O espaço da ação é contido no interior de um quadrinho. O tempo da narrativa avança por meio da comparação entre o quadrinho anterior e o seguinte ou é condensado em uma única cena. O personagem pode ser visualizado e o que ele fala é lido em balões, que simulam o discurso direto. As histórias em quadrinhos representam aspectos da oralidade e reúnem os principais elementos narrativos, apresentados com o auxílio de convenções que formam o que estamos chamando de linguagem dos quadrinhos. (RAMOS, 2010, p.18)

Essas tiras cômicas são produzidas em diferentes países e momentos históricos, havendo variados personagens. A sua leitura transcorre espaços e tempos, pois são lidas e procuradas por diferentes sujeitos. Todavia, a partir delas, em um contínuo processo de alteridade, produzem-se novos discursos e surgem novas interpretações. Alguns de afeto, reflexão e interesse em relação a elas; outros assumem uma posição diferenciada.

A escola é um espaço no qual as tiras são muito utilizadas atualmente. Nos livros didáticos e nos diversos exames aos quais os alunos são submetidos elas são veiculadas a exercícios de diferentes disciplinas. Estas aparecem ligadas ao ensino nas áreas de exatas, humanas e biológicas, tanto no dia-a-dia da sala de aula quanto nos diferentes tipos de provas, vestibulares e ENEM. Todavia esse gênero discursivo nem sempre foi aceito no contexto escolar.

Segundo Ramos (2010) as histórias em quadrinhos (como parte destas as tiras cômicas) não eram aceitas na sala de aula. Moacy Cirne em sua obra $A$ explosão criativa dos quadrinhos afirma que elas eram tidas como subliteratura considerada prejudicial ao desenvolvimento intelectual das crianças, havendo uma espécie de código moral que regia o uso destas no contexto escolar. No entanto as mudanças na concepção de educação no Brasil e do ensino da língua materna propostas a partir da década de 1970 irão trazer as tiras cômicas para universo da escola.

Santos (2007) discute essas mudanças que propulsionaram discursos sobre necessidade de novos e variados textos dentro do contexto escolar. Nas décadas de 70 e 80, com a influência da linguística estrutural e da teoria da comunicação, o ensino da língua materna fundamentou-se na concepção desta como um instrumento de comunicação. Uma diversidade de textos adentra a escola e os livros didáticos, no entanto, segundo o autor, são trabalhados de formas descontextualizadas, objetivando 


\section{Revista do SELL}

v. $4, n^{\circ} .1$

ISSN: $1983-3873$

promover modelos de boa escrita e a decodificação das mensagens ali contidas. As tiras neste momento começam a aparecer nos livros didáticos, mas como ilustrações de temas e capítulos.

A partir da década de 80 e 90, segundo Santos (2007), propulsiona-se o discurso da diversidade textual na escola, fundamentada em uma diferente concepção de língua: a de interação. Incentiva-se o ensino de diversos gêneros na sala de aula de forma contextualizada, a fim de reproduzir situações reais do uso dos gêneros e ensinar os diferentes propósitos sociais destes. Expande-se com esse discurso o uso das tiras em provas, livros didáticos. Ramos (2010) cita a inclusão destas nas provas dos vestibulares, nos Parâmetros Curiculares Nacionais e no Programa Nacional Biblioteca na Escola, levando-as de forma obrigatória para dentro da escola e para a prática do professor.

Entretanto as tiras muitas vezes, mesmo entrando no livro didático e nos exames, nem sempre são trabalhadas na sala como gênero. Alguns momentos ela entra por uma questão editorial, pela exigência do PCN. Todavia o humor, como característica marcante do gênero, e a linguagem autônoma dos quadrinhos, apontada por Ramos (2010), nem sempre são trabalhados, ficando algumas vezes em segundo plano diante dos aspectos gramaticais, ou da simples decodificações da mensagem ali contida. As aulas de língua materna nem sempre privilegiam o trabalho com as produções de sentido a partir das relações de humor e ironia no gênero. Bunzen (2007) comenta ainda que a presença de um texto no livro didático pode possuir diferentes objetivos. Este pode estar ali com vários objetivos, leitura e compreensão, estudo de marcas linguísticas, exemplos para produção textual, entre outros, e vai depender da atuação pedagógica o trabalho do texto como gênero, pensando na sua função social.

Entretanto ler e interpretar os enunciados concretos desse gênero discursivo tornase, em qualquer dos contextos de ensino, uma habilidade requerida aos alunos tanto nas atividades escolares diárias como nas provas. Os exames de caráter nacional e local e os vestibulares trabalham com elas nos mais variados tipos de exercícios. É exigido ao aluno responder questões que tenham como requisito a leitura das tiras de humor, as quais vêm do universo jornalístico e humorístico, onde são muitas vezes procuradas pelos leitores com o intuito de obter diversão, Todavia ao serem transpostas para um novo contexto, da escola e dos exames, o propósito de leitura destas sofre alterações.

Umas das tiras que se destaca, pelo seu uso em provas e livros didáticos, são as da Mafalda, personagem criada pelo argentino Joaquin Salvador Lavado Tejón (Quino) 


\section{Revista do SELL}

v. $4, n^{\circ} .1$

ISSN: $1983-3873$

nas décadas de 60 e 70. Publicadas no Brasil a partir da década de 70, são lidas em diversos contextos e veiculam-nas frequentemente ao contexto escolar.

A partir da atuação da presente autora e pesquisadora como professora do ensino médio, na rede privada de ensino, entre os anos de 2011 a 2013, percebeu-se, entre os alunos, variados discursos que expressavam desinteresse e até certos desafetos à presença das tiras de humor da Mafalda nas provas e exercícios das aulas de Língua Portuguesa, uma contradição ao prestígio que a personagem possui entre os leitores de quadrinhos no Brasil. Diante desse contexto de inserção das tiras na sala de aula e das diversas abordagens que elas podem ter nas aulas de língua portuguesa desenvolveu-se uma pesquisa de mestrado com objetivo de analisar a leitura delas na sala de aula e os fatores que levariam ao desinteresse e ao relacionar das tiras da Mafalda ao contexto escolar/avaliativo pelos alunos do terceiro ano do Colégio Adventista de Tupã, escola privada de atuação da professora/pesquisadora de língua portuguesa.

Este artigo, como parte da pesquisa de mestrado ${ }^{1}$, reflete, sob à luz dos conceitos do Círculo de Bakhtin, Volochinov/Mediviédev, sobre a relação entre os discursos presentes nas tiras de humor da Mafalda e como se dá a produção de discursos pelos alunos do terceiro ano do Ensino Médio de uma escola da rede privada de ensino, do interior de Tupã/ SP, frente a esse gênero, no contexto da sala de aula, com vistas à presença do(s) outro(s) do contexto escolar.

\section{Os sujeitos para o Círculo de Bakhtin}

Ao pensar nos diversos tipos de leituras dessas tiras, nas inúmeras relações entre discursos de variadas épocas e entre diferentes sujeitos, recorreremos aos estudos do Círculo de Bakhtin para analisar o discurso das tiras da Mafalda e a relação entre os alunos e elas. $\mathrm{Na}$ análise aqui apresentada, enfocaremos as relações de alteridade e a constituição do aluno como sujeito, bem como a relação entre aluno e tira, e ainda a

\footnotetext{
1 A presente pesquisa de mestrado, em desenvolvimento, tem como objetivo estudar a leitura e o discurso de alunos da turma do terceiro ano do Ensino Médio do Colégio Adventista de Tupã, interior de São Paulo, sobre as tiras de humor da Mafalda. Esta pesquisa surgiu a partir da atuação da pesquisadora, autora do artigo, como professora desses alunos e da existência de discursos de rejeição e desinteresse à leitura das tiras da Mafalda quando em contexto escolar e avaliativo. Para isso propôs-se uma pesquisa de campo, de caráter qualitativo, em que questionários e atividades que trabalhassem o humor e a crítica das tiras de humor da Mafalda fossem aplicados aos alunos. Selecionou-se portanto onze tirinhas da personagem retiradas da obra 10 anos com Mafalda. Essas atividades são trabalhadas em atividades dentro e fora da sala de aula, em contexto avaliativo e não avaliativo, de forma escrita e oral, individual e em grupos. A presente pesquisa encontra em desenvolvimento e obteve sua aprovação no comitê de ética da Fclar-UNESP/ Araraquara- Número CAAE- 19882513.5.0000.5400.
} 


\section{Revista do SELL}

v. $4, n^{\circ} .1$

ISSN: $1983-3873$

significação destas, provindas de tal relacionamento. Para isso, abordaremos, no presente artigo, os conceitos de sujeito/alteridade, significação e ato.

Ao longo dos estudos do Círculo de Bakhtin/Medviédev/Voloschinov as questões sobre o sujeito são suscitadas e discutidas. O sujeito aparece como social, histórico, responsável e responsivo, constituído de língua e linguagem. Geraldi (2010) explica, a partir das reflexões do Círculo, que o sujeito é responsável, consciente, respondente, incompleto, inconcluso, insolúvel, datado e não cartesiano.

O sujeito, de acordo com a filosofia da linguagem bakhtiniana, é um ser social, "um agente, um organizador de discursos, responsável por seus atos e responsivo ao outro" (SOBRAL, 2012, p. 24). Este é considerado situado e participativo, mas inserido em uma realidade sócio histórica.

Indivíduos de determinados contextos sócio-histórico-cultural constituem-se sujeitos na medida em que interagem com discursos de outros do presente, do passado ou do futuro, de maneira semiotizada. Todavia, cada um desses sujeitos é concreto e único, pertencente a determinadas realidades sócio históricas. Somente por meio dessa relação social com o outro em determinado momento e em dado lugar específicos é que o indivíduo constitui-se sujeito pela linguagem.

Através de enunciados concretos e únicos, cada um dialoga com variados discursos existentes em seu contexto ou em outras situações da grande temporalidade. Em cada espaço-tempo vigoram gêneros característicos da necessidade interacional existente pelos sujeitos. Por isso, estes, além de serem situados em um momento e em um local sócio histórico, são constituídos por língua e linguagem, pois o tornar-se sujeito ocorre nas muitas interações estabelecidas com o outro e essas só se dão por meio da linguagem, num determinado cronotopo (relação espaço-temporal, intrinsecamente indissolúveis).

Cada um desses discursos produzidos é sempre uma resposta ao(s) outro(s) existente(s) e desencadeará outras réplicas. Ao mesmo tempo em que eles não são inéditos, são sempre respostas no encadeamento de enunciados produzidos através do tempo e espaço. Por isso Geraldi (2010) afirma ser o sujeito respondente, pois

Neste caso, o ouvinte, ao perceber e compreender o significado linguístico do discurso, ocupa simultaneamente em relação a ele uma ativa posição responsiva: concorda ou discorda dele (total ou parcialmente), completa-o, aplica-o, prepara-se para usá-lo. Essa posição responsiva do ouvinte se forma ao longo de todo o processo de audição e compreensão desde o 


\section{Revista do SELL}

v. $4, n^{\circ} .1$

ISSN: $1983-3873$

seu início, às vezes literalmente a partir da primeira palavra do falante (BAKHTIN, 2011, p. 271)

Cada palavra suscita a existência de uma contra palavra. Todavia, todo sujeito é consciente e responsável por cada discurso proferido e as consequentes respostas, ecos e reverberações deste. O sujeito, portanto, não possui álibi na sua existência e é responsável por cada ato realizado.

Bakhtin (2010) discute a natureza do ato. Segundo as ideias ali presentes, o sujeito sempre assume uma posição consciente e axiológica no mundo e nas relações que estabelece com os outros ao seu redor. Todo discurso parte de uma posição valorativa ideológica e, em cada enunciado, sempre composto por signos ideológicos, encontramos o embate entre posicionamentos valorativos, sendo que "cada palavra se apresenta como uma arena em miniatura onde se entrecruzam e lutam os valores sociais de orientação contraditória". (BAKHTIN, 2004, p. 66).

De acordo com Bakhtin (2011), toda compreensão é prenhe de resposta e o ouvinte é também um falante. A compreensão passiva dos sentidos discursivos ouvidos é apenas um momento abstrato da compreensão ativamente responsiva real e plena que se atualiza na fala. Para o Círculo, o próprio falante espera uma atitude responsiva ativa do ouvinte. Afinal, todo falante é um respondente em maior e menor grau. Ele não é o primeiro falante do universo e pressupõe não só o uso da língua que usa como também a pré existência de enunciados.

Ao afirmar que o sujeito é inconcluso e incompleto, Geraldi ressalta a importância da alteridade para a sua (do eu) constituição. Afirma ele que

\footnotetext{
Deste movimento contínuo entre o eu e o outro, em que eu vivencio minha vida de dentro e o outro em dá completude do exterior, infere-se que os acabamentos ou as identidades serão sempre múltiplas no tempo e no espaço, pois a relação nunca é com somente um e mesmo outro e a vida não se resume a um e sempre mesmo tempo. (GERALDI, 2010, p. 289290)
}

Um sujeito não é capaz de dar-se o próprio acabamento. Para que um ser atinja certa completude é necessária a visão do outro. Somente este (o outro), por possuir uma distância e se encontrar deslocado do eu (num movimento exotópico), vai ver aquilo que o sujeito não vê em si próprio. Ao discutir a relação autor/herói, e a constituição e a obtenção do acabamento conferido ao herói pelo autor, Bakhtin (2011) fala em "excedente 


\section{Revista do SELL}

v. $4, n^{\circ} .1$

ISSN: $1983-3873$

de visão", ou seja, aquilo que o outro vê em mim e que eu não consigo ver para obter o meu acabamento como sujeito, da mesma maneira que eu vejo e completo o outro do lugar em que me encontro, fora dele. Segundo Geraldi (2010) os princípios utilizados por Bakhtin para explicar o acabamento do herói, servem também para analisar as relações de alteridade, pois o acabamento estético concedido pelo autor ao herói é resultante da necessidade absoluta do outro, da alteridade.

Nesse sentido é que cada discurso é produzido tendo em vista a existência do(s) outro(s). Este(s) influencia(m) naquilo que é dito, na forma e na maneira como é dito. Assim, a cada palavra dita ou posição tomada, o sujeito realiza, a partir da visão que tem de si e daquela que pensa ter o outro de si, em um determinado contexto sócio-históricocultural, seus atos e interpreta o mundo, tanto quanto este também o constitui.

Os enunciados configuram-se segundo os sujeitos envolvidos nas enunciações. A palavra sofre influência daquilo que é extra verbal. "A situação social mais imediata e o meio social mais amplo determinam completamente, e por assim dizer, a partir do seu próprio interior, a estrutura da enunciação" (Bakhtin/Voloschínov, 2012, p. 117).

Ao produzir um discurso haverá sempre relações de alteridade que influenciarão nas significações presentes. Bakhtin fala acerca da relação do eu para o outro, do outro para mim e do eu para mim.

Qual é a índole da concepção de mim mesmo, do meu eu em seu todo? Em que ele se distingue essencialmente da minha concepção do outro[...] o que compreende por eu quando falo e vivencio: "eu vivo", "eu morro", etc. ("eu sou", "eu não existirei" eu não existi"). Eu-para-mim, eu-para-ooutro, o outro-para-mim. O que em mim é dado imediatamente e o que é dado apenas através do outro. (BAKHTIN, 2011, p. 382)

Em cada ato, o sujeito sempre é influenciado, na produção de seus enunciados, pela visão que possui de si próprio, pela visão que possui dos outros e pelo pensamento acerca daquilo que os outros pensam dele. Sendo que um mesmo sujeito age de maneiras diferentes diante de sujeitos diferentes, em situações cronotópicas especificamente determinadas.

Ao estudar as tiras da Mafalda no contexto da sala de aula, observamos a constituição não só dos personagens, bem como do aluno como sujeito ao posicionar-se em relação ao discurso presente das tiras e dos outros que compõem o contexto escolar. 


\section{Revista do SELL}

v. $4, n^{\circ} .1$

ISSN: $1983-3873$

\section{O contexto de produção das tiras da Mafalda}

Conhecida como 'pequena contestadora', a personagem da Mafalda possui, em seu discurso, um tom crítico, reflexivo e questionador acerca do mundo, da sociedade e da ação dos outros sujeitos que a rodeiam. Como uma criança de uma Argentina que vivencia a Ditadura Militar, nas décadas de 60 e 70, indaga a sociedade em que se insere. Essas indagações, apesar de se materializarem nesse contexto histórico e social determinado, dialogam com conflitos e questionamentos da realidade atual. Os discursos presentes nas tiras transpassam a época de produção e escrita de Quino e relacionam-se com a atualidade.

Mafalda posiciona-se em relação ao micro e ao macro universo por meio do questionamento acerca das atitudes das demais personagens com quem ela se relaciona: pais, professores, amigos (Susanita, Manolito, Felipe, Liberdade, Miguelito), seu irmão caçula (Guile), entre outros. Estes representam, de certa forma, um microcosmo social da humanidade como um todo. Ela fala sobre a guerra do Vietnã, o descaso dos homens em relação aos outros e a mecanização do próprio homem.

Nas tiras, o discurso se constrói a partir de questionamentos dos atos e comportamentos dos outros. A pequena garota, uma criança, contesta acontecimentos e atos considerados comuns aos seus pais, aos seus colegas e até mesmo aos meios midiáticos e autoridades. A presença de um conflito de posicionamentos ideológicos é constante na tessitura do discurso verbal e visual das tiras da personagem. A pequena Mafalda está sempre refletindo sobre comportamentos triviais e ideologias oficiais, bem como posicionamentos alienados acerca dos acontecimentos sociais. $\mathrm{Na}$ condição de uma criança, coloca-se de forma reflexiva diante não só dos acontecimentos mundiais como também da postura dos outros em relação a estes.

A configuração estética da personagem, conjuntamente aos discursos presentes nas tiras, confirma essa oposição ao oficial. Mafalda sempre se apresenta trajada com um vestido vermelho. Esta cor do vestido, sempre constante, remete-nos a uma ideologia atuante nesse contexto ditatorial tão repressor das ditaduras. Vermelho é a cor da bandeira comunista, a qual representa a revolução em busca da liberdade, vinda da Revolução Francesa e da Revolução Russa, o sangue derramado da oprimida classe operária. 


\section{Revista do SELL}

v. $4, n^{\circ} .1$

ISSN: $1983-3873$

O contexto de produção das tiras da Mafalda é o de ditaduras não só na Argentina e no Brasil, mas em tantos outros países que por elas passaram nos anos 60 e 80 (como o Chile e a Venezuela, entre outros países). O fato da personagem se apresentar trajada pelas cores comunistas, bem como proferir discursos que indagavam o pensamento de sujeitos colocados como alienados e controlados pelo sistema vigente e pelas palavras da mídia nas tiras, é bastante transgressor. Mafalda representa o transgressor crítico visual e verbalmente.

O contexto de recepção, no entanto, varia segundo o momento histórico e os sujeitos presentes. Essa relação entre discursos constituídos por sujeitos sócio culturais diferentes, em tempos diferentes produz modificação na significação. No caso a ser descrito a seguir, trataremos da leitura e compreensão das tiras por jovens de momento e lugar históricos distintos daqueles da produção das tiras. O grupo de jovens em estudo, estão na faixa etária de 16 a 18 anos e integram uma turma do terceiro ano do ensino médio do Colégio Adventista de Tupã, totalizando 12 alunos. A disciplina em que a pesquisa se realiza é a de língua portuguesa, sendo realizadas atividades que exploram o humor e a crítica das tiras dentro e fora de contextos avaliativos.

\section{O discurso das tiras}

A partir do quadro teórico aqui apresentado e das considerações sobre o contexto de produção das tiras da Mafalda, analisamos abaixo algumas tiras da personagem e o discurso presente nelas. A partir da breve análise apresentada, discutiremos o contexto da sala de aula em que os alunos realizam as leituras destas..

Nesta análise, privilegiamos a construção do discurso e a produção de sentidos a partir das relações de alteridade. Relações estas presentes não só no processo de compreensão e produção de discursos pelos alunos, mas também na própria configuração dos personagens das tiras da Mafalda.

Atentemos às seguintes tiras: 


\section{Revista do SELL}

v. $4, n^{\circ} .1$

ISSN: $1983-3873$

Tira I
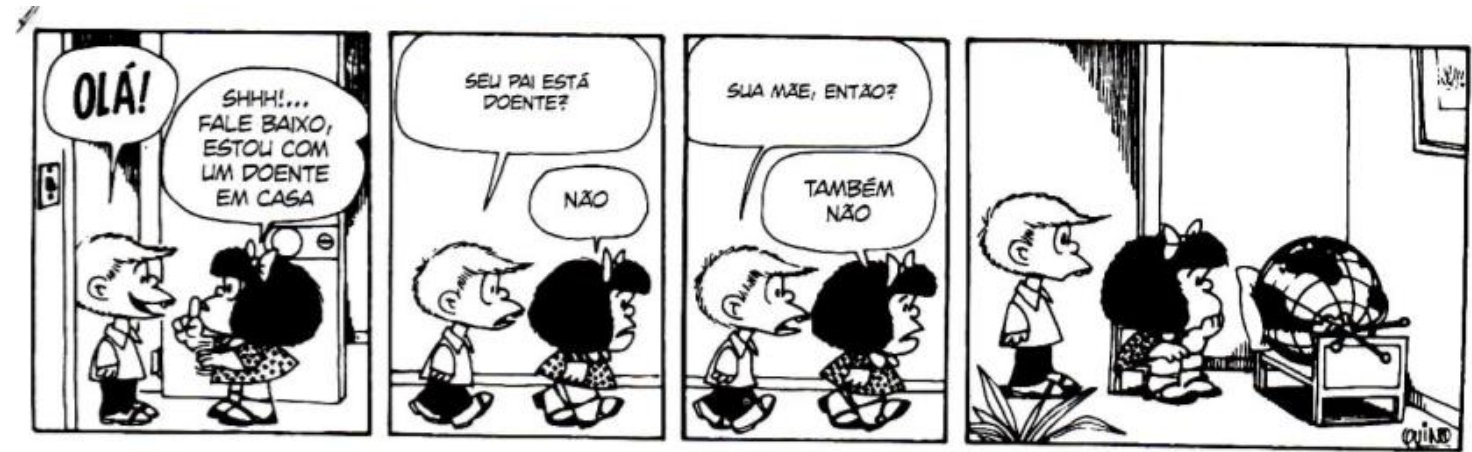

10 anos com Mafalda, 2010, p. 68

Tira II
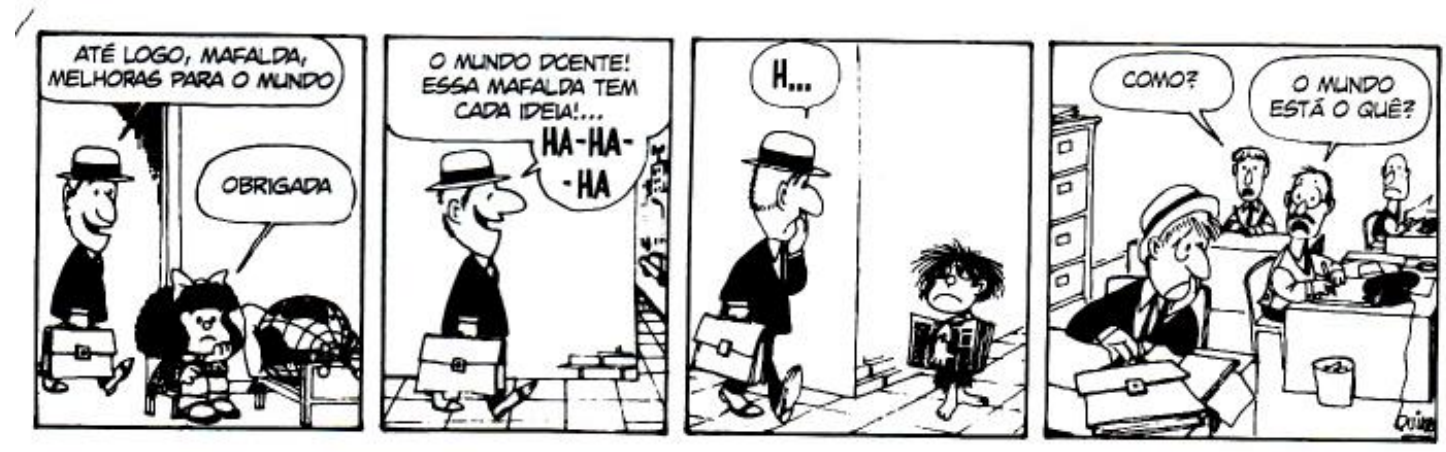

10 anos com Mafalda, 2010, p. 68

As tiras da Mafalda, na condição de enunciados, configuram-se como um campo dialógico, entre ideologias, pois se constituem por signos ideológicos. Esse embate é, segundo Bakhtin (2012), constitutivo da palavra e podemos dizer que tal embate é produzido nas tiras consideradas em uma relação de alteridade.

Nas tiras supramencionadas, a significação é produzida no estabelecimento de diálogos das personagens e com outros discursos, de outros sujeitos. Assumindo uma posição valorativa frente ao mundo, Mafalda opõe seu ponto de vista e seu posicionamento aos de outras personagens: Felipe e o pai da garota. Nesse movimento é que o discurso se constrói num embate entre posições axiológicas.

Baseados em Bakhtin (2012), podemos pensar na existência da ideologia oficial e na do cotidiano. A primeira é aquela consagrada, predominante e na qual muitas vezes os sujeitos se posicionam alienadamente. Já a segunda é aquela que vai se contrapor à primeira de forma a indagá-la. Felipe e o pai da Mafalda representam sujeitos que assumem posições alienadas em relação à condição do mundo. Estes semiotizam a voz daquela ideologia oficial, de um mundo ordenado, em boas condições. Já Mafalda 


\section{Revista do SELL}

v. $4, n^{\circ} .1$

ISSN: $1983-3873$

representa a contra palavra, a voz do despertar, do contrapor, aquela que assume a responsabilidade de alertar acerca de algumas condições de alienação - no caso das tiras em análise, a ideia de que o mundo está doente.

Os sujeitos alienados neste contexto, não se constituem em sujeitos que não possuem posicionamentos no ato de viver, mas segundo Bakhtin (2010) são sujeitos que assumem um falso álibi, ou seja, uma posição axiológica e conformista, ao não olharem criticamente para a realidade que os rodeia.

Na primeira tira, ao chegar à casa da Mafalda, esta afirma a Felipe que há um doente naquele lugar. Automaticamente, ele pensa em pessoas (mãe, pai). Todavia, ao chegar ao quarto e ouvindo as negativas de Mafalda, ele observa fixamente o globo terrestre sobre a cama. O mesmo acontece com o pai da personagem, que ironiza a ideia da filha de um mundo doente, acamado. Todavia, ao encontrar uma criança mendigando na rua, compreende o sentido da "doença" enunciada pela filha, reflete sobre isso e adere à ideia, reproduzindo-a no serviço por se apresentar preocupado, o que causa estranhamento de outros, que, espantados, sequer questionam ou refletem sobre tal ideia, apenas repetem, sem entender o sentido das palavras proferidas pelo personagem trabalhador, em ressonância ao discurso de Mafalda e à situação vista.

Nessa segunda tira, o pai da Mafalda aparece como representação de uma massa alienada, controlada pelo sistema vigente, o qual trabalha e vive sem posicionar-se criticamente a situação do mundo em que está inserido. A mesma postura é possível encontrar nos companheiros de repartição que também não compreendem a ideia de um mundo doente, vivendo segundo aquilo que é imposto pela mídia e por aqueles que detêm o poder. Todavia, o pai sofre um choque de realidade ao prestar atenção na criança de rua e, como estava pensando, de maneira irônica, no que Mafalda havia dito e compreender os sentidos do termo "doente" empregado pela filha, no último quadrinho, ele aparece em um processo de desalienação e despertar da consciência possível, disparada pelo contato com a realidade, desde o início metaforizada pela sua filha. Esse despertar angustiante o coloca num patamar diferente, em oposição aos colegas de trabalho, ainda alienados de si e do outro.

Todo momento, nas duas tiras, percebemos a constituição do sujeito na relação de alteridade. Mafalda se constitui como sujeito contestador frente à condição do mundo, colocado em diálogo pelos discursos sobre este provindos da mídia e o que ela observa. Felipe se constitui como sujeito na relação com a Mafalda e com a visão de um globo 


\section{Revista do SELL \\ v. $4, n^{\circ} .1$ \\ ISSN: $1983-3873$}

terrestre sobre a cama. O pai da Mafalda se constitui como sujeito na relação com a Mafalda, com a criança marginalizada e com os colegas da repartição.

Como explicitado no quadro teórico bakhtiniano, um sujeito só tem seu acabamento pelo outro. O pai da Mafalda só assume uma consciência possível, uma espécie de despertar, por meio do deslocamento da posição de alienação que ocupa, realizado em diálogo com outros sujeitos (Mafalda e a criança de rua).

Tanto na tira I como na II percebemos que Mafalda posiciona-se critica e ativamente diante da condição do mundo. Nas tiras como um todo, essa temática do mundo doente é comum, sempre afirmada pelo posicionamento da Mafalda. Há tiras como essas, em que ele aparece deitado sobre a cama; e há outras em que aparece enrolado em faixas e com termômetro. Esse mundo, segundo a personagem, está doente, mesmo sendo ele representação do mundo "real" - conforme afirma a própria Mafalda, ele é "um mundo em miniatura", o que significa que a condição doentia é minimizada e maximizada se pensarmos na semiotização do mundo enunciado e representado pelo globo terrestre. Na condição de enfermo, temos, no signo visual, um globo terrestre deitado sobre uma cama, na tira l; e, no verbal, apenas a menção a ele pelos signos "mundo" e "doente", o que ativa a memória do leitor acerca tanto de outras tiras em que essa mesma temática é assumida; quanto de situações vividas pelo mundo, seja do momento histórico de produção das tiras seja contemporâneo - podemos pensar que o mundo de hoje continua doente, uma vez que apresenta situações semelhantes às semiotizadas nas tiras (miséria e desigualdade sócio-político-econômica - o que é simbolizado pela presença da criança de rua, na tira II, por exemplo).

A construção do sentido acontece na relação de alteridade entre Mafalda e os outros personagens, bem como no jogo entre o verbal e o visual, e ainda entre a tira e seus leitores.

Tanto na tira I como na II há a expressão do deixar a posição de alienação por meio do visual (quadrinho com Felipe e Mafalda observando o mundo sobre a cama; quadrinho com pai da Mafalda deparando-se com uma criança de rua). A visualidade é tão importante quanto o verbal na construção dos sentidos e na produção dos discursos. Brait (2013) fala sobre a dimensão verbo-visual de um texto que é a "dimensão em que tanto a linguagem verbal como a visual desempenham papel constitutivo na produção de sentidos, de efeitos de sentido, não podendo ser separadas, sob pena de amputarmos uma parte do plano de expresso". 


\section{Revista do SELL}

v. $4, n^{\circ} .1$

ISSN: $1983-3873$

Outro aspecto importante é o sentido da expressão "mundo doente". No contexto de produção das tiras da Mafalda, décadas de 60 e 70, vários acontecimentos podem ser englobados a essa expressão. Podemos citar as ditaduras, a guerra do Vietnã, a guerra fria, entre outros; da mesma maneira que, tanto quanto hoje, a expressão pode se referir à miséria humana, à desigualdade social etc. Estar enfermo tem seu significado alterado segundo o momento histórico do leitor.

A significação do "mundo doente" vai ser construída na relação entre o discurso da personagem da tira e os discursos relacionados à condição do mundo no momento de leitura da ou considerando o seu momento de produção - depende do conhecimento de mundo do leitor. Os sujeitos que leem estabelecem diversas relações de alteridade. Cada um posiciona-se em relação a si próprio, ao discurso das tiras (pensando ou não no contexto de produção destas) e aos discursos dos outros, em seu contexto de leitura.

A alteridade influencia na constituição dos sujeitos das tiras e na constituição dos sujeitos leitores. Cada um ao se colocar como leitor assume uma posição e atua em relação ao conteúdo existente, produzindo novos sentidos.

\section{O ato dos alunos de ler as tiras}

Ler e compreender um texto é ir muito além das estruturas linguísticas de um enunciado. O aluno precisa compreender os sentidos pensando nas várias relações estabelecidas entre os sujeitos e na enunciação em que a tira é utilizada. Além disso a tira é um enunciado, como já dito, verbo-visual, portanto sua leitura deve estar voltada tanto para o signo verbal como o visual, que juntos produzem o sentido.

Ao ler e interpretar as tiras, o aluno está entrelaçado em relações com diferentes outros sujeitos e discursos. Estes, consequentemente, exercem influência sobre os dizeres e compreensões que o estudante tece acerca das tiras da personagem, pois, segundo Bakhtin,

aquilo que constitui a descodificação da forma linguística não é o reconhecimento do sinal, mas a compreensão da palavra no seu sentido particular, isto é, a apreensão da orientação que é conferida à palavra, por um contexto e uma situação precisos, uma orientação no sentido da evolução e não do imobilismo (Bakhtin/Voloschínov, 2012, p. 97)

Como já discutido no início do artigo o discurso da diversidade textual na educação trouxe para a escola variados textos, entre eles as tiras de humor, dentre as quais estão 


\section{Revista do SELL \\ v. $4, n^{\circ} .1$}

ISSN: $1983-3873$

as da Mafalda. Nesta parte do artigo a leitura das tiras da Mafalda na turma do 3ำ ano do ensino médio do Colégio Adventista de Tupã, a partir da pesquisa de campo em processo de realização nesta escola. As considerações e conclusões abaixo, no entanto são parciais, já que a pesquisa da qual emerge este artigo está em andamento. A pesquisa de campo encontra-se em andamento, no entanto os dados ainda estão em processo de coleta e análise.

A pesquisa de campo propôs o trabalho com onze tiras de humor da Mafalda na sala de aula do 3ำano do Ensino Médio no Colégio Adventista de Tupã/SP. Os sujeitos da pesquisa são 13 alunos, entre 16 e 18 anos. A pesquisadora responsável pelo estudo é a docente de língua portuguesa de tal turma. Como essa investigação originou-se da atuação da presente pesquisadora como docente desses alunos e nessa escola, escolheu-se esta como local de realização da pesquisa e aqueles como sujeitos a serem investigados.

A hipótese da qual se partiu a pesquisa referência desse artigo é a de que o desinteresse desses alunos em relação às tiras de humor da Mafalda está no fato destas vincularem-se ao contexto escolar e ao dos exames. Por isso privilegiou-se o trabalho com alunos que cursassem o terceiro ano do ensino médio, pois eles, na condição de prévestibulandos, leem as tiras da personagem com maior frequência dentro e fora do contexto avaliativo.

A metodologia da pesquisa fundamenta-se nas discussões sobre a relação entre o pesquisador e o seu outro, desenvolvidas por Amorim (2004). Segundo a autora, nas ciências humanas e no realizar de uma pesquisa de campo o pesquisador tem como objeto de pesquisa o outro, o qual se constitui sujeito segundo o conceito bakhtiniano já discutido acima. De caráter qualitativo, a pesquisa parte do pressuposto que a partir da análise desse quadro é possível gerar discussões sobre o processo de ensino do gênero tira de humor.

Foram aplicados dois questionários com vistas a investigar os hábitos de leitura dos alunos e o interesse deles para com as tiras de humor da Mafalda. Além disso, foram e serão propostas algumas atividades interpretativas das tiras de humor da personagem nas seguintes modalidades: em grupo, individual, avaliativas, não avaliativas, fora e dentro do momento da aula de Língua Portuguesa. Com isso visou-se investigar a leitura das tiras pelos alunos e a relação estabelecida entre eles, os discurso da Mafalda e os vários outros no contexto escolar. 


\section{Revista do SELL}

v. $4, n^{\circ} .1$

ISSN: $1983-3873$

As tiras da personagem acima discutidas foram trabalhadas nessas atividades propostas na pesquisa de campo. A primeira tira de humor foi proposta aos alunos como atividade de interpretação, dentro da sala de aula e fora do contexto avaliativo. Já a segunda será proposta dentro do contexto avaliativo e da sala de aula.

As tiras da Mafalda foram produzidas em um contexto sócio histórico diferente daquele em que estes alunos as leem. Ao propor a atividade com a primeira discutida nesse artigo, percebeu-se até o momento que o aluno trava um diálogo com ela, tendo como referência o momento em que está inserido. O "mundo doente", visto desse ponto de vista, ao mesmo tempo em que não é mais o mundo da guerra fria ou da guerra do Vietnã; é o mesmo mundo injusto e desigual de outrora, configurado de maneira diferente.

Quando questionados sobre essa doença do mundo, a resposta dos alunos a essa afirmação envolveram os seguinte fatores: poluição, desmatamento/destruição do meio ambiente, aquecimento global/efeito estufa, violência e terrorismo. Nota-se que ao pensar em um mundo com problemas, os alunos estabelecem um diálogo com discursos bem recorrentes em nossa sociedade sobre os problemas do planeta terra. Em nenhum dos discursos dos alunos houve menção aos fatos que afligiam a sociedade humana no contexto de produção das tiras da Mafalda. Mesmo havendo fatos mencionados que também são motivos da doença do mundo no momento da escrita de Quino, a relação entre estes dois contextos não foi realizada.

Houve também respostas que responderam à expressão mundo doente com afirmação da existência de um globo terrestre deitado sobre a cama. Percebe-se que estas não expressam o estabelecimento de um diálogo com outros discursos sobre um planeta que sofre. Se o aluno pensou em possíveis significados para a doença, não expressou, já que esta não era uma atividade avaliativa. A leitura dialógica, se estabelecida, não foi explícita pelo sujeito já que ler "não consiste em reconhecer as forma utilizadas, mas compreendê-la num contexto concreto preciso, compreender sua significação numa enunciação particular." (Bakhtin/Voloschínov, 2012, p. 96).

Bakhtin vai falar na compreensão que é ativa e criadora. "Assim a compreensão completa o texto: ela é ativa e criadora. A compreensão criadora continua a criação, multiplica a riqueza artística da humanidade. A cocriação dos sujeitos da compreensão. (Bakhtin, 2012, p. 378)". A relação desses alunos com as tiras resumiu-se, neste momento, pelo que foi expresso por eles, no decodificar dos signos verbais e visuais, sem o mobilizar de diálogos, ideologias e significados ali implicados. As tiras da Mafalda 


\section{Revista do SELL}

v. $4, n^{\circ} .1$

ISSN: $1983-3873$

envolvem, assim como outros gêneros, o refletir e dialogar com vários discursos e gêneros. Isto pode desenvolver certa resistência dos alunos às tiras da Mafalda, as quais aparecem em vestibulares e sistemas de avaliação, sendo difíceis de interpretar, como afirmado por esses alunos.

É importante ainda dizer que o não expressar sobre os possíveis significados do mundo pode ter sido uma própria escolha do aluno, tendo em vista que essa atividade não era um prova. Bakhtin (2011) afirma que todo enunciado produz resposta e reação, mesmo que esta não seja expressa. Talvez o não falar possa ser o próprio posicionamento do aluno à tira, ao discurso dela, a não avaliação e a figura do próprio professor.

Como já visto, as tiras da Mafalda dialogam com seus vários contextos históricos, tanto com o de sua produção quanto com aquele em que o aluno está inserido. Se o olhar do estudante volve-se somente para o significante sem mobilizar significados, os vários discursos presentes nas tiras não se materializam nas leituras do aluno. A Mafalda, personagem crítica e contestadora que transgride ao se opor ao senso comum, torna-se "chata", conforme muitos desses alunos pesquisados a designam, por não compreenderem os valores manifestos nas tiras de Quino. As denominadas tiras de humor não fazem sentido se as ideologias ali presentes não forem focalizadas. O humor passa a não existir, pois o aluno não encontra "graça" no que é crítico e não consegue compreender o humor como sátira e ironia.

O humor é outro elemento a ser discutido. Nas atividades de leitura das tiras propostas, perguntou-se se havia humor na tira. Tanto na tira I como na II o humor também foi questionado. Todavia na maioria dos discursos a resposta foi negativa. $O$ salunos afirmaram não encontrarem humor nas tiras, havendo somente crítica.

Diante desse quadro, foi possível constatar que o humor, por nem sempre ter uma abordagem como conteúdo na sala de aula e no livro didático (pensando no contexto de aula e nos livros didáticos dos alunos sujeitos dessa pesquisa) é visto pelo aluno como sinônimo de engraçado, daquilo que faz rir. Assim ao serem indagadod sobre o humor das tira da Mafalda, muitos afirmam não existir, já que os temas tratados por ela são trágicos. Quando afirmam a presença dele, referem-se a um humor negro.

Ler tiras da Mafalda é colocar-se diante de variados discursos e vozes. Nelas não só encontramos uma posição crítica em relação ao mundo, como também a construção do humor a partir dessa posição crítica da personagem Mafalda em relação aos outros. 


\section{Revista do SELL}

v. $4, n^{\circ} .1$

ISSN: $1983-3873$

Nas tiras dessa personagem inclusive, há a constituição de vários posicionamentos axiológicos perante a condição da humanidade e do mundo.

As relações de alteridade influenciam a constituição do sujeito bem como de seus discursos. Assim como nas tiras da Mafalda encontramos os sujeitos constituindo-se em relação ao(s) outro(s) e produzindo sentido nesses diálogos, o mesmo podemos observar no processo de leitura e construção do discurso desse aluno frente às tiras.

A relação do aluno com a Mafalda não se dá somente no ambiente da sala de aula, mas em diferentes lugares e tempos, envolvendo diversos sujeitos em situações de comunicação variadas. Dependendo da situação, os enunciados produzidos por esses sujeitos leitores são alterados.

Pode-se percebe que ao responder uma atividade proposta fora do contexto avaliativo, alguns alunos assumiram um posicionamento de não diálogo com outros discursos, estes, no entanto, em atividades/prova, elaboraram respostas mais elaboradas procurando ultrapassar o simples decodificar da mensagem ou descrição dos significantes verbo-visuais

Em um dos questionários aplicados perguntou-se aos alunos em que momentos eles liam as tiras da Mafalda. $80 \%$ das respostas relacionaram-nas ao contexto escolar (escola, livro, provas, exercícios de gramática). Outros $20 \%$ além de citarem o momento da aula, disseram lerem as tiras na internet. Isto mostra a grande veiculação dessa personagem ao contexto da aula para esses alunos, a qual exerce influência na constituição da opinião destes sobre as tiras e a personagen.

Além disso, constatou-se que os alunos não conheciam o contexto de produção das tiras. A configuração da personagem principal assim como dos seus amigos não eram familiares a esses alunos, já que estas estão, de acordo com os alunos em atividades escolares.

No contexto escolar, há diversos fatores que configuram o contexto de produção do discurso do aluno e o tipo de relação que ele estabelece com as tiras: a figura do professor, bem como a instituição escola, são sujeitos com os quais se estabelece uma hierarquia, por exemplo. Dependendo das relações cultivadas na escola, o professor pode tornar-se aquele sujeito que representa o poder canônico estrutural, pronto a corrigir o certo e o errado, punindo por meio da nota ou aquele sujeito que, junto com o aluno, reflete sobre possibilidades de construção dos sentidos, numa relação de ensinoaprendizagem contínuo. O aluno, dependendo das relações constitutivas da sala de aula 


\section{Revista do SELL \\ v. $4, n^{\circ} .1$}

ISSN: $1983-3873$

em que se insere, produz seu discurso a partir das tiras, pensando ou não em se posicionar frente aos discursos da Mafalda e ao do professor, da escola e da sociedade.

\section{Considerações finais}

As discussões já realizadas sobre as atividades aplicadas aos alunos do $3^{\circ}$ ano do Ensino Médio do colégio em estudo, já permitem algumas conclusões, ainda que parciais.

As tiras da Mafalda são fortemente vinculadas por esses alunos ao contexto escolar. Muitos afirmaram lê-las só em exercícios relacionados à sala de aula e às provas. Isto causa uma certa escolarização delas. É possível que essa veiculação à escola gere certo desinteresse á leitura da tira da personagem.

O trabalho com esses enunciados em sala de aula pode ser algo contextualizado e que destaque seus elementos como gênero tira, ou não. O humor é um elemento essencial às tiras, todavia os alunos em estudo não encontraram-no nas da Mafalda. Isso revela um déficit no conceito de humor, visto como algo engraçado, não crítico.

Ler e compreender tiras é relacionar-se com diferentes vozes e ideologias ali presentes. Os pontos de vistas e posicionamentos se encontram em embate não só no enunciado das tiras, mas naqueles travados a partir da leitura destas.

$\mathrm{O}$ ato de ler as tiras é sempre um ato de posicionar-se axiologicamente ao texto e aos outros envolvidos no contexto de leitura. $O$ fato destes alunos, sujeitos da pesquisa em debate, produzirem discursos que dialogaram ou não com outros discursos latentes naquele signo verbo-visual, representa uma escolha valorativa destes. Esta resposta que é axiológica constrói-se na relação com o(s) outro(s) envolvidos no processo de ler. Este aluno pode dizer ou não, de uma forma ou de outra, dependendo do tipo de posicionamento que desejar estabelecer em relação ao outro professor ou outro(s) aluno(s).

Nas leituras das tiras da Mafalda, estes sujeitos da pesquisa produziram seu discurso em relação a diferentes outros, os quais influenciam sobre os seus discursos e o seu posicionamento como sujeito social. A sala de aula configura-se, portanto um espaço de produção e diálogo de diferentes discursos e ideologias. Tanto os sujeitos alunos como o sujeito professor alternam-se nesse posicionar axiologicamente em relação aos seus vários outros sujeitos e enunciados (uns com os outros - tanto entre alunos, com os professores, com a escola, com a sociedade, com as personagens e com as tiras). 


\section{Revista do SELL \\ v. $4, n^{\circ} .1$ \\ ISSN: $1983-3873$}

As relações de alteridade estão presentes tanto na constituição do discurso das tiras da Mafalda quanto no ato de ler e produzir discursos acerca dessas tiras. $O$ estabelecimento de relações com o outro contribui para o surgimento de significações. Além disso, relacionar-se com este(s) outro(s) significa obter o próprio acabamento de si como sujeito, visto e constituído pelo outro enunciativo e enunciado.

\section{Referências}

AMORIM, M. O pesquisador e seu outro: Bakhtin nas ciências humanas. 6. ed. São Paulo: editora Musa, 2004

BAKHTIN, M. M. (VOLOCHINOV) (1929). Marxismo e filosofia da linguagem. 13. ed. São Paulo: Hucitec, 2012. . (1920-1974). Estética da Criação Verbal. 6. ed. São Paulo: Martins Fontes, 2011. . Para uma filosofia do ato responsável. São Carlos: Pedro e João Editores, 2010.

BRAIT. (Org.). Bakhtin: Conceitos-Chave. 5. ed. São Paulo: Contexto, 2012.

BRAIT, B. Olhar e ver: verbo-visualidade em perspectiva dialógica. In: Bakhtiniana Revista de Estudo do Discurso, São Paulo, v. 08, n.02, p. 90-105 , 2013

BUNZEN, C. O tratamento da diversidade textual nos livros didáticos de português: como fica a questão dos gêneros? In: CAVALCANTI, C. B. M; MENDONÇA, M; SANTOS, C. F. Diversidade textual: os gêneros na sala de aula. 1. Ed. Belo horizonte: Autêntica, 2007. CIRNE, M. BUM! A explosão criativa dos quadrinhos. Petrópolis: Vozes, 1970.

GERALDI, J.W. Sobre a questão do sujeito. In: PAULA, L. de; STAFUZZA, G. (Orgs.). "Círculo de Bakhtin: teoria inclassificável". Volume 1. Série Bakhtin - Inclassificável. Campinas: Mercado de Letras, 2010).

MENDONÇA, M. Ciência em quadrinhos: imagem e texto em cartilhas educativas. Recife: Bagaço, 2010.

PAULA, L. de; STAFUZZA, G. (Orgs.). "Círculo de Bakhtin: teoria inclassificável". Volume 1. Série Bakhtin - Inclassificável. Campinas: Mercado de Letras, 2010.

RAMOS, P. A leitura dos quadrinhos. São Paulo;. Contexto, 2010.

SANTOS, C. F. O ensino da língua escrita na escola: dos tipos aos gêneros textuais. In: CAVALCANTI, C. B. M; MENDONÇA, M; SANTOS, C. F. Diversidade textual: os gêneros na sala de aula. 1. Ed. Belo horizonte: Autêntica, 2007. 


\section{Revista do SELL}

v. $4, n^{\circ} .1$

ISSN: $1983-3873$

SOBRAL, A. Ato / atividade e evento. In: BRAIT, B. Bakhtin conceitos-chave. 5. ed. São Paulo: Contexto, 2012.

QUINO. 10 anos com Mafalda. Trad. de Monica Stahel. São Paulo: Editora Martins Fontes, 2010. 